\title{
A cheat sheet to navigate the complex maze of exclusivities in the United States
}

\author{
"It is imperative during due diligence to determine the length of market exclusivity a \\ potential licensed product may be entitled to."
}

Keywords: data exclusivity $\bullet$ market exclusivity $\bullet$ patent exclusivity $\bullet$ regulatory exclusivity

Pharmaceutical exclusivities serve help to provide protection from competitors for innovative drugs and biologics by deferring market entry for a limited period of time. After entering the US market, pharmaceutical products can benefit from a variety of exclusivities, through the regulatory process (through the US Food and Drug Administration [FDA]) or the patent system (through the United States Patent and Trademark Office [USPTO]) or a combination of the two. Patents protect $\mathrm{R} \& \mathrm{D}$ investment by blocking a competitor, such as a generic manufacturer or another innovator, from entering the market with the same or similar product. Although FDA's main function is to protect consumers from unsafe, ineffective and fraudulently marketed products, since the passage of the Orphan Drug Act in 1983 [1] and the Drug Price Competition and Patent Term Restoration Act in 1984 (Hatch-Waxman Act) [2], the FDA also administers regulatory exclusivities. The Hatch-Waxman Act requires the FDA to publish the Orange Book, identifying drug products approved on the basis of safety and effectiveness. The Orange Book lists patents and use codes provided by the drug application owner purported to protect each drug and the FDA is obliged to list them. The Orange Book is available electronically for searching at the FDA webpage [3]).

It is imperative during due diligence to determine the length of market exclusivity a potential licensed product may be entitled to. To facilitate discussions and decision making based on this multifaceted issue, a summary of US exclusivities for drugs and biologics was created and is presented in Figure 1. This cheat sheet can be used as a reference card to navigate the complex maze of exclusivities, to envision possible scenarios to extend exclusivity and to make informed decisions.

\section{Discussion}

In the United States, innovator companies can benefit from several sources of exclusivity to delay market entry of a competitor's product. Laws and regulations supporting exclusivities are different for drugs versus biologics. Pharmaceutical products containing small molecule active ingredients with welldefined structure, obtained by chemical synthesis in a reproducible manner and which can be thoroughly characterized by analytical methods are considered drugs. Biologics are products whose active ingredient is a large molecule, of complex structure, generally derived from living material, usually not fully characterized and presenting a potential risk for immune response in patients. These include vaccines, blood and its components, allergenic, somatic cells, gene therapy, tissues and recombinant proteins, among others. Some products, for example, certain peptides may be approved as drugs or as biologics. Drug approval is regulated by the Federal Food, Drug and Cosmetic Act [4], whereas biologics approval is mostly regulated by the Public Health Service Act [5].

\section{Patent exclusivities for drugs}

One way in which a drug can enjoy market exclusivity is through patent protection. Currently, most US patents expire 20 years after their filing date, unless the patent term is adjusted. A patent term can be shortened if

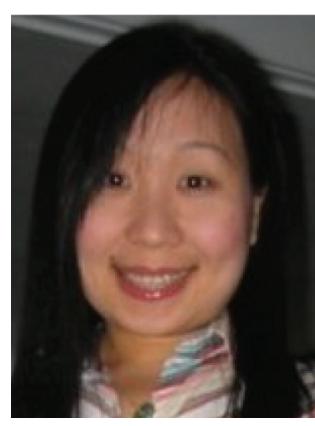

Bo Peng

Author for correspondence: Ironwood Pharmaceuticals, 301 Binney Street, Cambridge, MA 02142, USA

silpeng@gmail.com

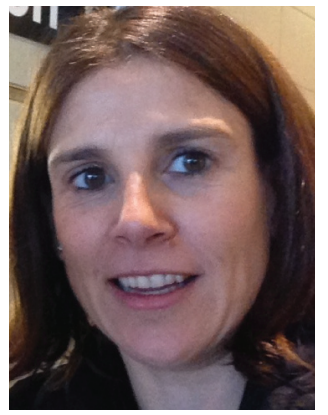

Marta Cavero Tomas Ironwood Pharmaceuticals, 301 Binney Street, Cambridge, MA 02142, USA 


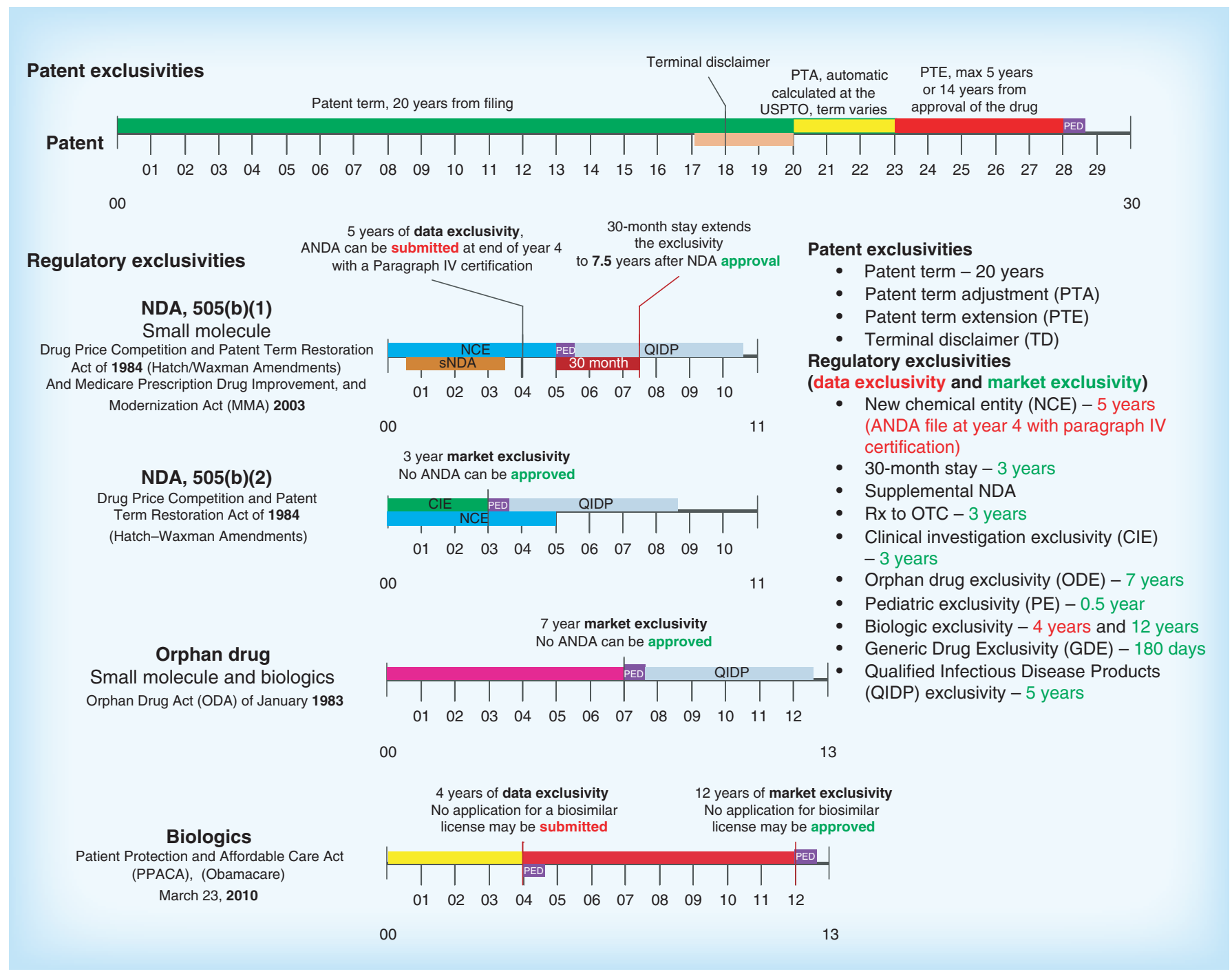

Figure 1. A cheat sheet of exclusivities in the United States. All timelines start at year zero. Each interval represents a new year. The horizontal color blocks represent the length of each exclusivity period.

For color images please see www.future-science.com/doi/full/10.4155/ppa.14.30.

a terminal disclaimer [6] is filed with respect to another commonly owned patent with an earlier expiration date. The patent term can also be extended, either through patent term adjustment (PTA) [7] or through patent term extension (PTE) [8]. PTA is intended to compensate for administrative delays caused by the USPTO during patent prosecution whereas PTE is intended to compensate for regulatory delays in obtaining FDA approval. PTE is capped at 5 years and the remaining patent life after PTE may not extend beyond 14 years after approval of the drug. Furthermore, only the first approval of a new active ingredient qualifies for a PTE, and only one patent may be extended per new active ingredient. The patent must be Orange-Book listable.

In order for a generic competitor to win approval of a drug under the Hatch-Waxman scheme (through filing of an Abbreviated New Drug Application (ANDA), it must certify that: there are no patents in force covering the product; it will not launch its product until after the expiration of all Orange Book-listed patents; and the Orange-Book listed patents are invalid, unenforceable or will not be infringed. ANDA or 505(b)(2) applications (covered under section 505(j)(2)(A)(vii) of the FDCA) must contain a patent certification making one of the following statements: no patent information on the drug product has been submitted to FDA; patent has expired; the patent expiration date or patent is invalid; or the patent is unenforceable or will not be infringed. The latter is commonly known as a Paragraph IV certification. If patents are in force, the competitor's product can only be approved upon their expiration date. A notice of Paragraph IV certification must be provided to each owner of the patent subject of the certification and to the holder of the approved New Drug Appli- 
cation (NDA) to which the competitor product refers. The submission of a drug application for a patented drug is an infringing act in itself if the drug product is intended to be marketed before the expiration of the patents. A list of ANDA drug challenges is maintained at the FDA's Office of Generic Drugs. However, there is not such listing for other types of drug applications.

\section{Regulatory exclusivities for drugs}

Regulatory exclusivities provide parallel market protection for an approved drug, which can extend exclusivity beyond the patent term or in the absence of patent coverage. Nonpatent regulatory exclusivities include: new chemical entity (NCE) exclusivity [9]; clinical investigation exclusivity (CIE) [10,11]; orphan drug exclusivity (ODE) [1]; pediatric exclusivity (PE) [12]; generic drug exclusivity (GDE) $[2,14]$ and qualified infectious disease products (new as of 2012) exclusivity.

There are three main FDA routes of approval of a pharmaceutical product; for an NCE or a drug containing an active moiety that has never been approved by the FDA, a NDA or 505(b)(1) application is submitted [9]. An active moiety or active ingredient is the molecule or ion, excluding appended portions that make the drug an ester, salt or other noncovalent derivative (e.g., a complex), responsible for the physiological or pharmacological action of the drug. An NDA includes results of human clinical trials sufficient to prove safety and efficacy. For follow-on products including new dosage forms, new strengths, routes of administration, dosing regimens or indications, a 505(b)(2) [10,11] application is submitted that relies, at least partly, on published information or FDA's past findings of safety and efficacy for which the applicant has no right of reference. 'Right of reference or use' under 21 C.F.R. $\$ 314.3$ is defined as the authority to rely upon an investigation for the purpose of obtaining approval of an application, including the ability to make available the underlying raw data from the investigation for FDA audit [13]. Generic products are approved through an Abbreviated New Drug Application (ANDA) or 505(j) application $[2,14]$. Generic drugs contain the same active ingredient, in the same dosage form, same strength and route of administration as an approved drug (the 'reference drug'). Generic products do not need to duplicate safety and efficacy clinical trials; but only prove 'bioequivalence' to the reference drug. If the applicant has right of reference, the follow-on product can be approved through a supplement to a previously approved application (NDA or an ANDA) [13]. These applications are referred to as sNDA or sANDA. The supplement type refers to the kind of change that is approved by FDA, for example, CMC, patient population (e.g., pediatric) or a formulation (efficacy) supplement.
The Hatch-Waxman Act provides up to 5 years of market exclusivity to companies introducing an NCE to the market via an NDA. It also provides up to 3 years market exclusivity for conducting trials via a new NDA, sNDA or 505(b)(2) application, supporting changes to marketed products. During the 5 years of NCE exclusivity, the FDA cannot approve or even accept a competitor's 505(b)(2) or ANDA for a product based on the same active ingredient, regardless of indication, with one exception: if the 505(b)(2) or ANDA filer submits a Paragraph IV certification [14], the FDA can accept the application 1 year before the expiration of the 5 year exclusivity. Hence, the NDA holder enjoys 4 years of data exclusivity during which another applicant cannot rely on clinical data obtained by the NDA holder, but no approval can occur until the 5 -year expiration date. If the patent holder sues within 45 days, FDA approval of the ANDA or 505(b)(2) is stayed for 30 months. In practice, this may extend the NCE market exclusivity to 7.5 years after NDA approval. For all patents listed on or after 18 August 2003 , only one 30-month stay per generic application is allowed per generic ANDA and it is limited to patents listed prior to the generic ANDA. FDA can at any time accept and approve a second NDA for the same active moiety that relies on clinical trials conducted by the second NDA applicant.

Three years of CIE are granted to sponsors of new clinical trials of approved drugs leading to changes in the marketed products pursuant to a new NDA, sNDA, 505(b)(2) or for a prescription to over-thecounter switch. CIE blocks approval of a competitor's 505(b)(2) or ANDA for the same product modification, but not their submission (no data exclusivity applies). In order to support the CIE the filer has to conduct or sponsor new human clinical trials that are 'essential to approval of the new product' and which are not bioequivalence or bioavailability studies.

ODE of 7 years is granted to drugs for treatment of a rare disease or condition (in the United States defined as affecting less than 200,000 people or where there is no reasonable expectation of recoupling costs of developing the drug after marketing). ODE is a robust market exclusivity that blocks approval of any $505(\mathrm{~b})(1), 505(\mathrm{~b})(2)$ or $505(\mathrm{j})$ application directed to the same drug, for the same disease. It also provides other benefits, for example, tax credits, grants, etc. ODE may be granted for the same drug and different indication or for the same indication and different drug. FDA may even accept and approve applications for the same drug and indication, if the applicant can demonstrate that the product is 'clinically superior', that is, safer, more effective or significantly more convenient. 
PE of 6 months, extending any existing market or patent exclusivity, is granted after completion of FDArequested clinical trials in a pediatric population, even if the studies are not successful. PE blocks approval of any 505(b)(2) or ANDA application but not their acceptance. Once obtained for a drug, it applies to all other market or patent exclusivities covering drugs from the applicant containing the same active ingredient.

GDE grants 180 days to the first ANDA application submitting a 'substantially complete' ANDA containing a Paragraph IV certification. It blocks approval, but not submission, of subsequently filed ANDAs containing Paragraph IV certifications. The 180 days start counting when commercial marketing is initiated. Under some circumstances GDE can be shared or forfeited [14].

Starting in 2012, qualified infectious disease products exclusivity adds 5 years of exclusivity for qualifying products to any other existing regulatory exclusivity period (e.g., NCE, CIE, ODE and PE).

\section{Exclusivities for biologics}

Approval of biologics involves filing of a biological license application or a supplemental biological license application, both regulated under the Public Health Service Act. In 2010 the Biologics Price Competition and Innovation Act of 2009 (BPCIA [15]) was enacted providing a regulatory pathway for follow-on biologics (FOBs), or products that are 'biosimilar' to and/ or 'interchangeable' with previously licensed biologics. It grants the reference biologic manufacturer 12 years of market exclusivity after approval, of which, the first 4 years provide data exclusivity (no biosimilar application accepted by the FDA during that period relying on data obtained by the reference drug manufacturer). There is no 30-month stay for FOB; ODE and PE apply to biologics the same way they do to drugs.

An 'interchangeable' biosimilar may be substituted for the pioneer product without the intervention of a healthcare provider who prescribed the reference product. Noninterchangeable biosimilars receive no exclusivity. For interchangeables, a subsequent FOB

\section{References}

1 FDA guidance document: "21 C.F.R Part 316 - Orphan Drugs."

www.fda.gov/RegulatoryInformation/Legislation/

FederalFoodDrugandCosmeticActFDCAct/

SignificantAmendmentstotheFDCAct/OrphanDrugAct/ default.htm

2 FDA guidance document: "Abbreviated New Drug Application (ANDA): Generics."

www.fda.gov/Drugs/DevelopmentApprovalProcess/ application approval is blocked until the earlier of: 1 year after commercial marketing of the first interchangeable FOB, 18 months after resolution of a suit brought by the patent holder of the pioneer biologic against the first interchangeable FOB or if the first interchangeable $\mathrm{FOB}$ is sued for patent infringement, approval of the second FOB is stayed for 42 months if litigation is still ongoing or if the first generic is not sued, the second generic can be approved 18 months after approval of the first interchangeable FOB.

\section{Future outlook}

The patent and drug regulation systems are interwoven in the Hatch-Waxman scheme creating considerable complexity and uncertainty for pharmaceutical companies. The situation for biologics is even more uncertain, since the laws regulating approval of biosimilars and interchangeables are still evolving and the debate regarding the 12-year exclusivity for a first licensed biological product is still ongoing.

\section{Acknowledgements}

This article was developed from a presentation given by B Peng at the Patent Information Users Group (PIUG) 2014 Biotechnology Conference, Cambridge, MA, USA, 25-27 February 2014. The authors would like to thank the current and former colleagues from Ironwood Pharmaceuticals, specially D Reasner, D Sanchez, C Pierce, K Brown, Z Zdraveski and T Garcia-Rivas for helpful discussions.

\section{Financial \& competing interest disclosure}

B Peng was an employee of Ironwood Pharmaceuticals (January 2007-2014) and is currently an employee of Editas Medicine. She is also a member of the Patent Information Users Group, Inc. (PIUG). M Cavero-Tomas is an employee of Ironwood Pharmaceuticals. The authors have no other relevant affiliations or financial involvement with any organization or entity with a financial interest in or financial conflict with the subject matter or materials discussed in the manuscript apart from those disclosed.

No writing assistance was utilized in the production of this manuscript.

HowDrugsareDevelopedandApproved/ApprovalApplications/ AbbreviatedNewDrugApplicationANDAGenerics/default. htm

3 Orange Book: "Approved Drug Products with Therapeutic Equivalence Evaluations." www.accessdata.fda.gov/scripts/cder/ob/default.cfm

4 Federal Drug and Cosmetic Act. www.house.gov/legcoun/Comps/DCA_CDM.pdf

5 Public Health and Safety Act. www.house.gov/legcoun/Comps/PHSA_CMD.pdf 
6 PTO, Manual of Patent Examining Procedure; Chapter 1400; Section 1490: "Statutory disclaimers, including terminal disclaimers."

www.uspto.gov/web/offices/pac/mpep/s1490.html

7 PTO, Manual of Patent Examining Procedure; Chapter 2700; Section 2701: "Contents and term of patent; provisional rights." www.uspto.gov/web/offices/pac/mpep/s2701.html PTO, Manual of Patent Examining Procedure, Chapter 2700, Section 2750: "Patent Term Extension for Delays at other Agencies." www.uspto.gov/web/offices/pac/mpep/s2750.html

921 U.S.C. $\$ 355 ; 505$ (b) (1) section of the FDCA. www.gpo.gov/fdsys/pkg/USCODE-2010-title21/pdf/ USCODE-2010-title21-chap9-subchapV-partA-sec355.pdf

10 FDA guidance documents: "Guidance for Industry, Applications Covered by Section 505(b)(2).” www.fda.gov/downloads/Drugs/

GuidanceComplianceRegulatoryInformation/Guidances/ UCM079345.pdf

11 "Guidance for Industry, Listed Drugs, 30-Month Stays, and Approval of ANDAs and 505(b)(2) Applications Under Hatch-Waxman, as Amended by the Medicare Prescription Drug, Improvement, and Modernization Act of 2003." www.fda.gov/downloads/drugs/ guidancecomplianceregulatoryinformation/guidances/ ucm072887.pdf

12 FDA guidance document: "Guidance for Industry, Qualifying for Pediatric Exclusivity Under Section 505A of the Federal Food, Drug, and Cosmetic Act." www.fda.gov/downloads/drugs/developmentapprovalprocess/ developmentresources/ucm049924.pdf

13 Guidance for Industry. Changes to an approved NDA or ANDA.

www.fda.gov/downloads/Drugs/

GuidanceComplianceRegulatoryInformation/Guidances/ ucm077097.pdf

14 FDA guidance document: "Guidance for Industry: 180Day Generic Drug Exclusivity Under the Hatch-Waxman Amendments to the Federal Food, Drug, and Cosmetic Act." www.fda.gov/downloads/drugs/ guidancecomplianceregulatoryinformation/guidances/ ucm079342.pdf

15 FDA draft guidance document: "Scientific Considerations in Demonstrating Biosimilarity to a Reference Product, February 2012."

www.fda.gov/downloads/Drugs/

GuidanceComplianceRegulatoryInformation/Guidances/ UCM291128.pdf 